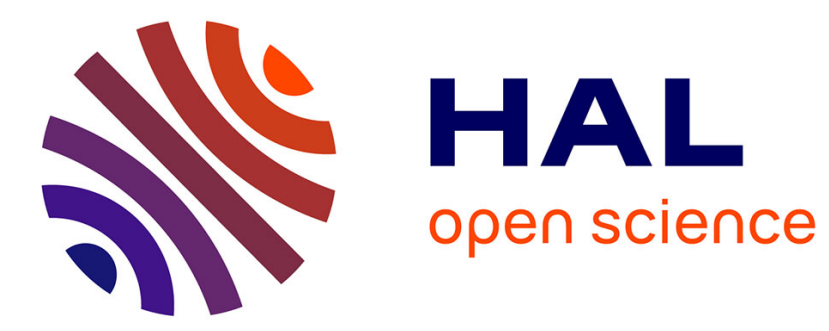

\title{
Internal Friction and Creep-Recovery in Indium
}

H. Ledbetter, N. Sizova, S. Kim, H. Kobayashi, S. Sgobba, L. Parrini

\section{To cite this version:}

H. Ledbetter, N. Sizova, S. Kim, H. Kobayashi, S. Sgobba, et al.. Internal Friction and CreepRecovery in Indium. Journal de Physique IV Proceedings, 1996, 06 (C8), pp.C8-317-C8-319. 10.1051/jp4:1996869 . jpa-00254677

\section{HAL Id: jpa-00254677 https://hal.science/jpa-00254677}

Submitted on 1 Jan 1996

HAL is a multi-disciplinary open access archive for the deposit and dissemination of scientific research documents, whether they are published or not. The documents may come from teaching and research institutions in France or abroad, or from public or private research centers.
L'archive ouverte pluridisciplinaire HAL, est destinée au dépôt et à la diffusion de documents scientifiques de niveau recherche, publiés ou non, émanant des établissements d'enseignement et de recherche français ou étrangers, des laboratoires publics ou privés. 


\title{
Internal Friction and Creep-Recovery in Indium
}

\author{
H. Ledbetter, N. Sizova, S. Kim, H. Kobayashi*, S. Sgobba** and L. Parrini*** \\ Materials Science and Engineering Laboratory, National Institute of Standards and Technology, Boulder, \\ Colorado 80303, U.S.A. \\ * National Research Laboratory of Metrology, Tsukuba, Ibaraki, Japan \\ ** CERN, Geneva, Switzerland \\ *** Ecole Polytechnique Fédérale de Lausanne, Institut de Génie Atomique, 1015 Lausanne, Switzerland
}

\begin{abstract}
Using low-stress pseudoshear deformation, we measured the ambient-temperature creep-recovery behavior of polycrystalline indium. The $\dot{\varepsilon}-\sigma$ diagram shows three regions with increasing stress: stress exponents of 1.05 , 7.4, and 2.0. The diagram resembles remarkably the dislocation-velocity-shear-stress diagrams reported for various materials by many authors, who interpreted the diagrams by dislocation dynamics. Applying an extended Burgers model (two Kelvin-Voigt elements) gave for the three regions the following relaxation times $\tau_{2}$ and $\tau_{3}$ (in seconds): (1) 11,123 ; (2) 10,132 ; (3) 12,154 . Thus, $\tau_{1}$ is nearly stress independent, and $\tau_{2}$ increases with increasing stress. Laplacean transformation of our $\varepsilon(t)$ measurements to get the retardation-time distribution function $g(\ln \tau)$ indicates in all three regions a strong peak near $\tau_{2}=3 \mathrm{~s}$ and a weaker, broader peak near $\tau_{3}=150 \mathrm{~s}$. These agree surprisingly well with the Burgers dashpot-spring-model results. We analyzed the recovery part of the strain $\varepsilon(t)$ to obtain $Q^{-1}(f)$ curves.
\end{abstract}

\section{INTRODUCTION}

Creep is not only an important technological problem but also a basic solid-state physics problem where deformation often occurs by dislocation mechanisms. Measurements of creep strain $\varepsilon(t)$ can be converted to $Q^{-1}(f)$, internal friction dependence on frequency.

The present study focuses on a soft metal: indium, which at ambient temperature exists at about $70 \%$ of its melting point, thus in the high-temperature region. Indium shows a body-centered-tetragonal crystal structure. In the alternative face-centered-tetragonal basis, the unit-cell dimensions are 4.947 and $4.598 \AA$. Thus, with an aspect ratio of 1.08 , indium is not far from face-centered cubic. Indium's physical properties, such as elastic stiffness and thermal expansivity, are moderately anisotropic.

\section{MATERIAL}

From a commercial source, we obtained 3-kg ingots with $99.99 \%$ purity, the principal impurities being $\mathrm{Cu}, \mathrm{Fe}, \mathrm{Mn}$. We obtained specimens by casting the indium into aluminum molds in a nitrogen atmosphere (99.95\%, dry). The optical microstructure showed equiaxed grains with a wide grain-size distribution: 0.1-1 mm. By Archimedes's method, at $295 \mathrm{~K}$, we found a mass density of $7.283 \mathrm{~g} / \mathrm{cm}^{3}$, nearly exactly the x-ray-diffraction handbook value of 7.285. Using a pulse-echo measurement method, we found the following elastic constants: bulk modulus $42.2 \mathrm{GPa}$, Young modulus $12.6 \mathrm{GPa}$, shear modulus $4.35 \mathrm{GPa}$, Poisson ratio 0.450 .

\section{MEASUREMENTS}

To measure the creep-recovery curves at various stresses, we used a method described by Kobayashi and coworkers [1]. We applied a pseudoshear force to a 1-cm-cube specimen by using calibrated masses 
to a maximum of a few kilograms. We detected displacement within $10 \mathrm{~nm}$ by using a commercial dualfrequency Michelson laser interferometer and two cube-corner reflectors.

\section{DISCUSSION}

In our creep-recovery measurements, the most conspicuous feature is the enormous viscoplastic component. The total strain $\varepsilon(t)$ contains three parts: elastic, anelastic, viscoplastic. That is,

$$
\varepsilon=\varepsilon_{e}+\varepsilon_{a}+\varepsilon_{v} \text {. }
$$

We modeled the $\varepsilon(t)$ curve with a mechanical dashpot-and-spring model [2]:

$$
2 \varepsilon=\frac{\sigma_{0}}{M_{1}}+\frac{\sigma_{0}}{\eta_{1}} t+\frac{\sigma_{0}}{M_{2}}\left(1-e^{-t / \tau_{2}}\right)+\frac{\sigma_{0}}{M_{3}}\left(1-e^{-t / \tau_{3}}\right) .
$$

Here, $t$ denotes time after loading, $\sigma_{0}$ applied constant shear stress, $M_{i}$ spring stiffnesses, $\eta$ viscosity, $\tau_{i}$ retardation times related to the spring stiffnesses and to the in-parallel dashpot viscosities by $\eta_{i}=M_{i} \tau_{i}$. We added the second anelastic Kelvin-Voigt unit to the Burgers model to achieve better measurementmodeling agreement. We determined $\dot{\varepsilon}(t=\infty)$ analytically by differentiating Eq. (2) and using the coefficients determined by fitting Eq. (2) to the $\varepsilon(t)$ measurements.

The $\dot{\varepsilon}-\sigma$ measurements show several interesting features: At low stresses, $\dot{\varepsilon} \sim \sigma^{n}$ with $n=1.05$ \pm 0.08 , corresponding closely to Newtonian viscosity. At higher stresses, $\dot{\varepsilon} \sim \sigma^{n}$ with $n=7.4 \pm 0.04$. We guessed, but did not verify, that the Newtonian region corresponds to Harper-Dorn creep [3]. The powerlaw region served as a focus of a few previous studies, both experimental and theoretical $[4,5]$. For this region, Weertman's model [6] predicts $n=4.5$. His model presumes annihilation by dislocation climb of opposite-sign edge dislocations on parallel slip planes. Clearly, for our indium results, we require a model predicting $n \simeq 7$. At still higher stresses, the slope decreases to about $n=2.0$. (In Fig. 2, these three regions are labeled 1, 2, 3 in order of increasing stress.)

Some authors [7] attribute the lower slope change to the Peierls stress. We prefer to invoke the following relationship for steady-state creep (plastic-strain rate):

$$
\dot{\varepsilon}=N(t) b v \text {. }
$$

Here, $N$ denotes mobile-dislocation density, $b$ Burgers-vector magnitude, $v$ dislocation velocity. Thus, an $\dot{\varepsilon}-\sigma$ diagram should resemble a $v-\sigma$ diagram. Comparisons confirm this [8-10]. Various dislocation mechanisms associated with the S-shape $\nu-\sigma$ curves are described elsewhere [8-10].

We can obtain the retardation-relaxation times $\tau$ from either a two-Burgers-units model, Eq. (2), or another, model-independent approach: spectral analysis. Sgobba and coworkers [11] described how the relaxation-time spectral function can be approximated:

$$
\left.g(\ln \tau) \simeq\left[\frac{d}{d(\ln t)}-\frac{d^{2}}{d(\ln t)^{2}}\right] \varepsilon(t)\right|_{\tau=t / 2} .
$$

Figure 1 shows the calculation results: a strong, sharp peak near $3 \mathrm{~s}$ and a weaker, broad peak near $150 \mathrm{~s}$. These results agree surprisingly well with the two-Burgers-units dashpot-spring-model results. As described by Nowick and Berry [12], agreement between approximate expressions and "exact" results for the standard anelastic solid is often reasonably good.

From spectral analysis, Nowick and Berry [13] gave an approximate relationship:

$$
Q^{-1} \simeq-\left.\left.\left.\frac{\pi}{2} \frac{d \ln J_{1}(\omega)}{d \ln \omega}\right|_{\omega=1 / t} \simeq \frac{\pi}{2} \frac{d \ln J(t)}{d \ln t}\right|_{t=1 / \omega} \simeq \frac{\pi}{2} \frac{d \ln \varepsilon(t)}{d \ln t}\right|_{t=1 / \omega}
$$

Figure 2 shows the results obtained from Eq. (5) for the recovery part of $\varepsilon(t)$. 


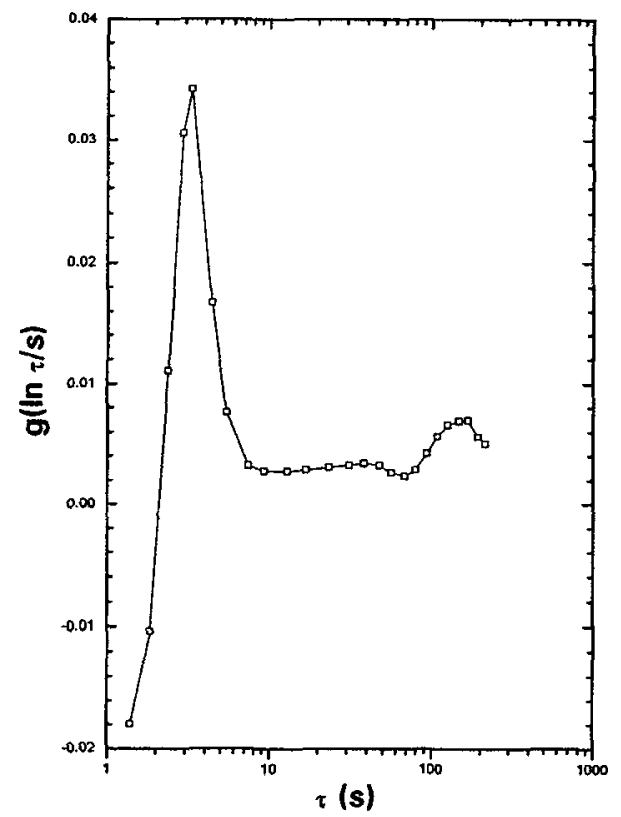

Figure 1: Spectrum of retardation times showing two distinct peaks.

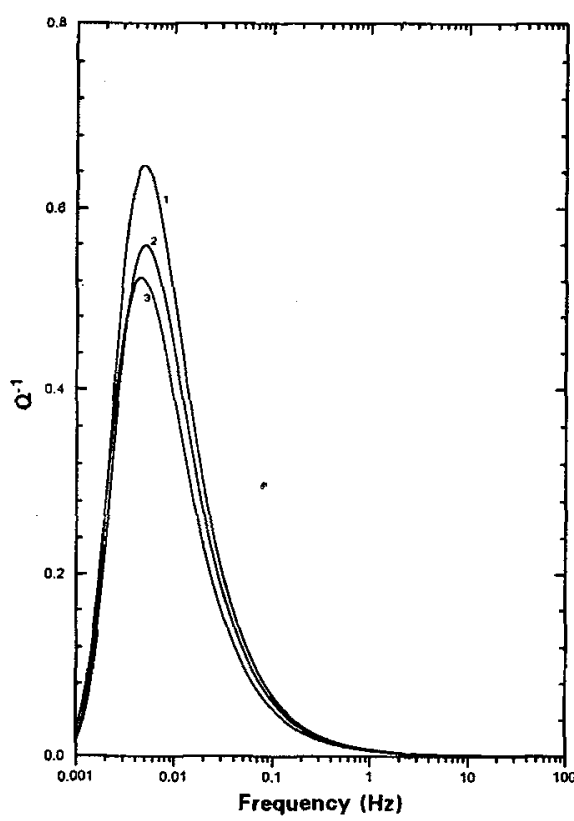

Figure 2: Internal-friction-frequency curves obtained from Eq. (5).

\section{CONCLUSIONS}

1. The viscoplastic strain dominates the strain response.

2. Good agreement with a dashpot-spring model requires using two, not one, Burgers units.

3. Retardation times from spectral analysis agree reasonably well with those from a dashpot-spring model.

4. The $\dot{\varepsilon}-\sigma$ diagram shows three regions, as found in velocity-stress diagrams.

5. Analyzing the $\varepsilon(t)$ diagram gives well-defined $Q^{-1}(f)$ peaks near $0.01 \mathrm{~Hz}$.

A full version of this study will appear elsewhere [14].

\section{References}

[1] Kobayashi, H., Takahashi, H., and Hiki, Y., Int. J. Thermophys. 16 (1995) 577.

[2] Nowick, A. and Berry, B., Anelastic Relaxation in Crystalline Solids (Academic, New York, 1972) chap. 3.

[3] Harper, J. and Dorn, J., Acta Metall. 5 (1957) 654.

[4] Weertman, J., Trans. AIME 218 (1960) 207.

[5] Chevalier, G., McCormick, P., and Ruoff, A., J. Appl. Phys. 38 (1967) 3697.

[6] Weertman, J., J. Appl. Phys. 28 (1957) 362.

[7] Wang, J., Scr. Metall. 29 (1993) 733.

[8] Gilman, J., Micromechanics of Flow in Solids (McGraw-Hill, New York, 1969) p. 178.

[9] Haasen, P., Physical Metallurgy (Cambridge UP, Cambridge, 1978) p. 262.

[10] Alshits, V. and Indenbom, V., in Dislocations in Solids, vol. 7 (North-Holland, Amsterdam, 1986) p. 46.

[11] Sgobba, S., Parrini, L., Künzi, H.-U.,and Ilschner, B., J. Alloys Compounds 211/212 (1994) 608.

[12] Reference [2] pp. 49, 89.

[13] Reference [2] p. 90.

[14] Ledbetter, H., Kim, S., Sizova, N., Kobayashi, H., Sgobba, S., and Parrini, L., submitted.

U.S.-government contribution; not subject to copyright. 